\title{
ANALISIS BEBAN KERJA DAN KEBUTUHAN KARYAWAN PEMUPUKAN KELAPA SAWIT DI PT. WIRA INOVA NUSANTARA KABUPATEN KUTAI TIMUR KALIMANTAN TIMUR
}

\section{(ANALYSIS OF WORK LOAD AND NEEDS OF FERTILIZER OIL PALM IN PT. WIRA INOVA NUSANTARA KUTAI TIMUR KALIMANTAN TIMUR REGENCY)}

\author{
Aries Rimbawan* \\ ${ }^{1}$ Politeknik Pertanian Negeri Samarinda, Kampus Gunung Panjang, Jl. Samratulangi, \\ Samarinda, Indonesia \\ ariesrimbawan43@gmail.com
}

\begin{abstract}
This research is motivated by the growing area of land or land used for oil palm business, in the industrial and cultivation sectors and in the company also has a design in determining the desired employee needs including determining the right employee needs according to their workload. emban. This study aims at workload to analyze workload, effective working time, and the amount of labor required by the fertilizer division. The study was conducted using the work sampling method to determine the pattern of activities in the use of working time. Fertilizing employees for 3 working days for each employee with an observation time interval of 10 minutes. This study uses a qualitative approach by means of observation and interviews.

The results showed a job description of each employee in the fertilization section. The effective working time owned by employees is 59,976 minutes per year with effective working days for a year is 204 days. The total annual workload of the surface part is 60,384 minutes with a total of 13 employees. These results indicate that the number of employees who are deficient will have an impact on the completion time of the task. Therefore, it is advisable for the section that handles employees at PT Wira Inova Nusantara to review the distribution of employees in order to produce optimal and timely work.

It is hoped that it can provide information that can be useful for those who read or who want to develop existing methods to be better and more effective methods and can be used as an evaluation in planning and determining the needs of fertilization employees for future consideration and evaluation.
\end{abstract}

Keywords : Fertilization Unit Workload Analysis

\section{PENDAHULUAN}

Kelapa Sawit (Elaeis Guineensis Jacq) merupakan tanaman penghasil minyak nabati yang paling produktif dibandingkan dengan seluruh tanaman penghasil minyak nabati lainnya. Menurut Sunarko (2014) Potensi tanaman kelapa sawit selama 25 tahun dengan manajemen tanaman yang baik, rata rata produktivitasnya dapat mencapai 18 ton TBS/tahun, bahkan lebih banyak. tergantung dari kualitas benih dan kelas lahan, serta manajemen produksi, khususnya teknik budidaya yang diterapkan. Indonesia merupakan penghasil minyak kelapa sawit terbesar di dunia. Perkebunan kelapa sawit terbesar berada di daerah Sumatra dan Kalimantan.

Salah satu tindakan yang amat penting dalam kultur teknis tanaman kelapa sawit adalah pemupukan. Tujuan pemupukan adalah menambahkan ketersediaan unsur hara di dalam tanah agar tanaman dapat menyerap nya sesuai dengan kebutuhan. Pemupukan harus dilakukan secara teratur menurut bagan pemupukan, sedang bagi pemupukan dibuat berdasarkan hasil percobaan pemupukan tanaman kelapa sawit pada jenis tanah tertentu (Mangoensoekarjo dan Semangun, 2000). Salah Satu efek pemupukan yang sangat bermanfaat yaitu meningkatkan 
kesuburan tanah yang menyebabkan tingkat produksi tanaman menjadi relatif stabil serta meningkatkan daya tahan tanaman terhadap serangan penyakit dan pengaruh iklim yang tidak menguntungkan (Pahan,2012).

Dalam pekerjaan pemupukan sangat dibutuhkan nya pengukuran kerja yaitu untuk mengetahui target waktu yang harus dicapai oleh seseorang karyawan untuk menyelesaikan suatu pekerjaan. Target waktu yang ditetapkan untuk suatu pekerjaan tidak akan benar apabila metode untuk melaksanakan pekerjaan tersebut berubah, material yang dipergunakan sudah tidak lagi sesuai dengan spesifikasi semua, kecepatan kerja mesin atau proses produksi lainnya berubah pula, dan kondisi-kondisi kerja lainnya sudah berbeda dengan kondisi kerja pada saat waktu baku tersebut ditetapkan (Wignjosoebroto, 2000).

Berdasarkan pada penjelasan sebelumnya, maka dapat dibentuk beberapa rumusan masalah sebagai berikut :

1. Bagaimana deskripsi pekerjaan karyawan pemupukan di PT Wira Inova Nusantara?

2. Bagaimana beban kerja dan waktu kerja efektif yang digunakan karyawan pemupukan?

3. Bagaimana jumlah kebutuhan karyawan pemupukan yang ideal pada PT. Wira Inova Nusantara?

4. Bagaimana alternatif solusi manajerial yang dapat disarankan?

Penelitian ini terfokus pada kajian masalah sumber daya manusia yaitu mengenai pengukuran beban kerja dan jumlah kebutuhan karyawan pada PT Wira Inova Nusantara. Sasaran penelitian yaitu karyawan yang bekerja pada bagian pemupukan di afdeling 1 (Sungai Petar Estate). Adapun objek penelitian adalah beban kerja yang dihasilkan karyawan pemupukan ketika menyelesaikan pekerjaannya.

Berdasarkan perumusan masalah yang terdapat pada uraian sebelumnya nya, maka tujuan yang ingin dicapai pada penelitian ini adalah :
1. Mengidentifikasi deskripsi pekerjaan karyawan permukaan di PT Wira Inova Nusantara.

2. Menganalisis beban kerja dan waktu kerja efektif yang digunakan karyawan pemupukan.

3. Menganalisis jumlah kebutuhan karyawan pemupukan yang ideal pada ada PT Wira Inova Nusantara.

4. Memberikan saran manajerial untuk perusahaan pada karyawan pemupukan

Hasil dari penelitian ini diharapkan dapat bermanfaat kepada :

1. Bagi peneliti yaitu dapat menambah wawasan tentang permasalahan manajemen sumber daya manusia dalam suatu perusahaan

2. Perusahaan, sebagai rekomendasi dalam pengelolaan jumlah sumber daya manusia yang efektif dan efisien dalam mencapai tujuan perusahaan.

3. Bagi para pembaca pada umumnya, agar menambah wawasan dan ilmu pengetahuan.

\section{METODOLOGI}

\section{Tempat Dan Waktu}

PT. WIRA INOVA NUSANTARA yang berada di Sungai Petar Estate Desa Perupuk, Kecamatan Sangkulirang, Kabupaten Kutai Timur, Provinsi Kalimantan Timur. Penelitian dilaksanakan pada tanggal 20 November s/d 20 Desember 2019 sesudah Praktik Kerja Lapangan.

\section{Alat Dan Bahan}

Lembar work sampling; kamera; stopwatch; alat tulis; alat pengolah data; kertas hvs; kertas folio; printer; objek sampel (karyawan pemupukan).

\section{Teknik / Metode Pengambilan Data}

Pengumpulan data primer mengenai karyawan diperoleh melalui metode work sampling yaitu pengamatan terhadap aktifitas yang dilakukan oleh karyawan selama jam kerja dengan jarak waktu pengamatan setiap sepuluh menit. Aktifitas yang diamati dalam penelitian menggunakan work sampling 
dikelompokkan menurut kategori kegiatan produktif, tidak produktif, dan pribadi. Kegiatan produktif merupakan semua kegiatan yang berhubungan dengan penyelesaian pekerjaan seperti yang terdapat pada uraian tugas-tugas pokok di setiap unit di pabrik dan kebun. Kegiatan tidak produktif meliputi kegiatan yang dilakukan karyawan yang tidak bermanfaat bagi pekerjaan seperti terlambat, bermalas-malasan, mengobrol, dan sebagainya. Kegiatan pribadi merupakan kegiatan yang dilakukan karyawan untuk menghilangkan kelelahan. Hasil pengamatan kemudian dicatat dalam formulir work sampling. Pengumpulan data primer berupa standar kemampuan rata-rata waktu penyelesaian dan kuantitas beban tugastugas pokok pekerjaan di bagian pemupukan dilakukan melalui metode wawancara terhadap karyawan.

Selain itu, pengumpulan data untuk tujuan mengidentifikasi tugas-tugas pokok pekerjaan bagian pemupukan dilakukan dengan metode gabungan wawancara dan observasi. Adapun data sekunder dikumpulkan melalui studi kepustakaan yang dilakukan dengan cara membaca dan mengutip informasi dari buku, skripsi, situs-situs internet, maupun dokumen-dokumen yang dimiliki oleh institusi.

Metode pengumpulan sampel yang digunakan adalah purposive sampling, yaitu teknik pengambilan sampel dengan menentukan karakteristik tertentu (Sugiyono, 2008). Kriteria yang dipakai dalam penelitian ini adalah karyawan pemupukan, subjek sampel dari 16 karyawan di ambil 12 orang di PT.Wira Inova Nusantara, Sungai Petar Estate berstatus aktif (bekerja secara penuh di PT.Wira Inova Nusantara, Sungai Petar Estate divisi 1).

\section{Prosedur Kerja}

1. Mempersiapkan Perlengkapan Penelitian

2. Menuju Lokasi Pengambilan Sampel

3. Merekam Waktu Kerja Karyawan

4. Mencatat Pada Lembar Work Sampling
5. Menganalisis Data

6. Mengolah Data

Analisis Data

1. Menetapkan Waktu Kerja

Waktu kerja yang dimaksud adalah waktu kerja efektif, artinya waktu kerja yang secara efektif digunakan untuk bekerja. Waktu kerja efektif terdiri atas hari kerja efektif dan jam kerja efektif. Hari kerja efektif adalah jumlah hari dalam kalender dikurangi hari libur dan cuti. Perhitungannya adalah sebagai berikut : Hari Kerja Efektif $=\{A-(B$ $+C+D)\}$ Keterangan : $A=$ Jumlah hari menurut kalender $B=$ Jumlah hari Sabtu dan Minggu dalam setahun $C=$ Jumlah hari libur dalam setahun $D=$ Jumlah cuti tahunan Jam kerja efektif adalah jumlah jam kerja formal dikurangi dengan waktu kerja yang hilang karena tidak bekerja (allowance) seperti buang air, melepas lelah, istirahat makan, dan sebagainya. Allowance diperkirakan rata-rata sekitar $30 \%$ dari jumlah jam kerja formal. Dalam menghitung jam kerja efektif sebaiknya digunakan ukuran 1 minggu.

2. Menyusun Waktu Penyelesaian Tugas

Waktu penyelesaian tugas merupakan hasil perkalian dari jumlah beban suatu tugas pokok dengan standar kemampuan rata-rata waktu penyelesaian tugas tersebut.

Tabel 1. Rumus Perhitungan Waktu Penyelesaian Tugas

\begin{tabular}{clll}
\hline No. & $\begin{array}{l}\text { Uraian } \\
\text { Tugas } \\
\text { Pokok }\end{array} \quad$ BT & SKR & $\begin{array}{l}\text { WPT } \\
\text { (BT x } \\
\text { SKR) }\end{array}$ \\
\hline 1. & & & \\
\hline 2. & & & \\
\hline 3. & & \\
\hline 4. & & \\
\hline 5. & & \\
\hline$\ldots$. & & \\
\hline & $\sum$ WPT & \\
\hline
\end{tabular}

Keterangan :

BT = Jumlah beban tugas dalam waktu tertentu

SKR = Standar kemampuan rata-rata waktu penyelesaian tugas 
WPT = Waktu penyelesaian tugas

$\Sigma \quad=$ Jumlah

3. Menghitung Jumlah Kebutuhan Pekerja

Kebutuhan Pekerja $=$

$\frac{\sum \text { Waktu Penyelesaian Tugas }}{\sum \text { Waktu Kerja Efektif }} \mathrm{x}$ N

Keterangan :

$\Sigma=$ Jumlah

$\sum_{N}=$ Karyawan

\section{HASIL DAN PEMBAHASAN}

A. Profil Perusahaan

PT. Wira Inova Nusantara (PT.WIN - Susuk Estate, Sungai Petar Estate, Factory Susuk) didirikan berdasarkan akta pendirian No 14 tanggal 25 Februari 2003. Pada tanggal 19 Agustus 2005 PT WIN ( Susuk Estate, Sungai Petar Estate, Factory Susuk) telah memperoleh Izin Usaha Perkebunan (IUP) seluas 10.000 ha berdasarkan surat keputusan Bupati Kutai Timur : 500/258/EK-VIII/2005 dan pada tanggal 28 Desember 2007 telah memperoleh IUP seluas \pm 6.606 ha berdasarkan surat keputusan Bupati Kutai Timur No:743/02.188.45/HK/XII/2007. Surat sekertaris daerah Kabupaten Kutai Timur tanggal 17 November 2008 nomor : 100/800/pem-1/XI/2008.

Berdasarkan surat keputusan Bupati Kutai Timur nomor : 188.4.45/118/Eko.1-VII/2013 tentang Izin Usaha Perkebunan Pengolahan (IUP-P) Pabrik Kelapa Sawit (PKS) kapasitas 60 ton TBS/jam yang terletak di desa Susuk Luar Kecamatan Sandaran Kabupaten Kutai Timur dengan SK Izin Mendirikan Bangunan (IMB) nomor : 348/BP2T2.1/X/2013 tanggal 11 Oktober 2013.

Izin Usaha Perkebunan kepada PT. Wira Inova Nusantara untuk keperluan Budidaya Perkebunan Kelapa Sawit seluas $\pm 7.009,17$ ha (Tujuh Ribu Sembilan Koma Tujuh Belas Hektar) yang terintegrasi dengan Pabrik Kelapa Sawit (PKS) dengan unit pengolahannya Crude Palm Oil (CPO) berkapasitas 60 ton TBS/jam, di Kecamatan Sandaran Kabupaten Kutai Timur sebagai mana peta Izin Usaha Perkebunan yang tercantum pada lampiran keputusan ini. PT. Wira Inova Nusantara (WIN) - Sungai Petar Estate memiliki luas areal perkebunan 4.633 terbagi atas 8 divisi yaitu : Divisi I dengan luas areal 737 ha, Divisi II dengan luas areal 585 ha, Divisi III dengan luas areal 611 ha, Divisi IV dengan luas areal 552 ha, Divisi V dengan luas areal 730 ha, Divisi VI dengan luas areal 480 ha, Divisi VII dengan luas areal 589 ha, Divisi VIII dengan luas areal 350 ha.

Untuk unit pemupukan sendiri di Divisi I berjumlah 16 orang terdiri dari 1 mandor pemupukan, 3 karyawan pelangsir pupuk dan 12 karyawan penabur pupuk.

B. Tugas Pokok Pekerjaan Karyawan Pemupukan

Tabel 2. Tugas Pokok Karyawan Pemupukan

\begin{tabular}{|c|c|c|}
\hline Tugas Pokok & No. & $\begin{array}{c}\text { Uraian Tugas } \\
\text { Pokok }\end{array}$ \\
\hline \multirow{10}{*}{$\begin{array}{c}\text { Aplikasi } \\
\text { pupuk } \\
\text { anorganik } \\
\text { pada } \\
\text { Tanaman } \\
\text { Menghasilkan } \\
\text { Kelapa Sawit }\end{array}$} & 1 & Apel pagi \\
\hline & 2 & $\begin{array}{l}\text { Mempersiapkan } \\
\text { alat kerja }\end{array}$ \\
\hline & 3 & $\begin{array}{l}\text { Mengenakan } \\
\text { Alat Pelindung } \\
\text { Diri (APD) }\end{array}$ \\
\hline & 4 & $\begin{array}{l}\text { Menuju blok } \\
\text { atau lokasi } \\
\text { kerja }\end{array}$ \\
\hline & 5 & $\begin{array}{l}\text { Membuka } \\
\text { karung pupuk }\end{array}$ \\
\hline & 6 & $\begin{array}{l}\text { Menuang } \\
\text { pupuk ke dalam } \\
\text { ember }\end{array}$ \\
\hline & 7 & $\begin{array}{l}\text { Mengangkat } \\
\text { ember yang } \\
\text { telah diisi } \\
\text { pupuk }\end{array}$ \\
\hline & 8 & $\begin{array}{l}\text { Berjalan dan } \\
\text { menabur pupuk } \\
\text { pada areal } \\
\text { piringan pokok } \\
\text { sawit }\end{array}$ \\
\hline & 9 & $\begin{array}{l}\text { Berjalan } \\
\text { kembali untuk } \\
\text { mengisi ember } \\
\text { pupuk }\end{array}$ \\
\hline & 10 & $\begin{array}{l}\text { Perpindahan } \\
\text { jalur berikutnya }\end{array}$ \\
\hline
\end{tabular}


Berdasarkan informasi mengenai pekerjaan pemupukan yang dikumpulkan melalui wawancara dan observasi, maka tugas pokok pekerjaan beserta uraian tugas Karyawan Pemupukan (KPpk) dapat disimpulkan seperti pada tabel 2
Uraian tugas pokok nantinya akan digunakan untuk menganalisis beban kerja dan kebutuhan karyawan pemupukan di afdeling satu.

C. Karakteristik Responden

Tabel 3. Karakteristik Karyawan Pemupukan Afdeling I

\begin{tabular}{lllll}
\hline Responden & Jenis Kelamin & Usia (Tahun) & Pengalaman Kerja & Tingkat Pendidikan \\
\hline KPpk 1 & P & 30 & 5 & SD \\
\hline KPpk 2 & P & 40 & 3 & SD \\
\hline KPpk 3 & P & 41 & 6 & SD \\
\hline KPpk 4 & P & 46 & 7 & SD \\
\hline KPpk 5 & P & 48 & 6 & SD \\
\hline KPpk 6 & P & 50 & 7 & SD \\
\hline KPpk 7 & P & 26 & 1 & SMP \\
\hline KPpk 8 & P & 33 & 5 & SMP \\
\hline KPpk 9 & P & 37 & 4 & SMP \\
\hline KPpk 10 & P & 27 & 3 & SMA \\
\hline KPpk 11 & P & 28 & 2 & SMA \\
\hline KPpk 12 & P & 29 & 2 & SMA \\
\hline
\end{tabular}

d. Karakteristik Berdasarkan Jenis Kelamin

Banyaknya jumlah karyawan perempuan disebabkan sifat pekerjaan yang dilakukan memerlukan ketelitian karena kegiatan pemupukan adalah pekerjaan beresiko tinggi terhadap kesehatan maupun keselamatan kerja. Karena dalam pekerjaan ini, terjadi kontak langsung antara pekerja dengan bahan kimia aktif.

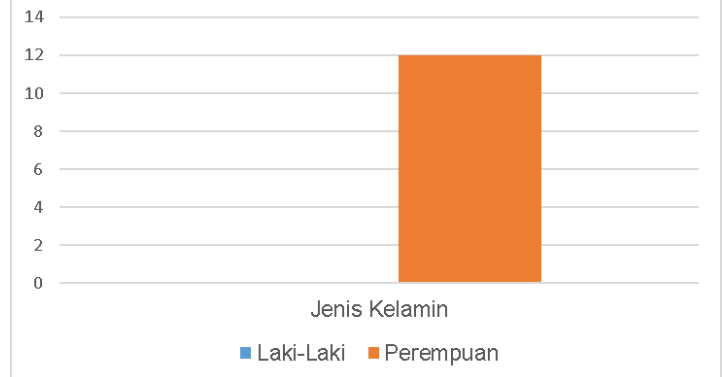

Gambar 1. Jenis Kelamin Karyawan Pemupukan

e. Karakteristik Berdasarkan Usia

Dari hasil analisis menunjukkan bahwa kategori usia berada diantara 26 50 tahun. Faktor usia penting untuk dipahami karena karyawan yang berbeda usia memiliki kebutuhan terhadap bentuk pekerjaan yang berbeda. Selain itu, perbedaan usia dapat mengakibatkan perbedaan pada kinerja dan sikap karyawan.

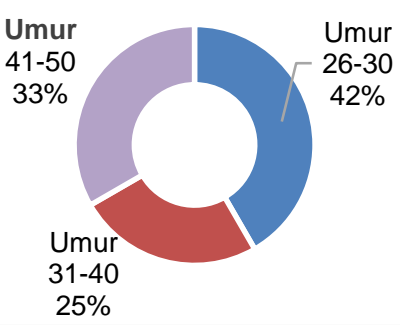

Gambar 2. Rata-Rata Umur Karyawan Pemupukan

f. Karakteristik Berdasarkan Pengalaman Kerja dan Perbandingannya

Karyawan akan mampu bekerja dengan baik dan bertahan beberapa lama disuatu unit kerja apabila pekerjaan mereka sesuai dengan keahlian yang dimiliki setiap karyawan. Pengalaman Kerja yang dimiliki oleh setiap karyawan pemupukan berada diantara 1 sampai 7 tahun.

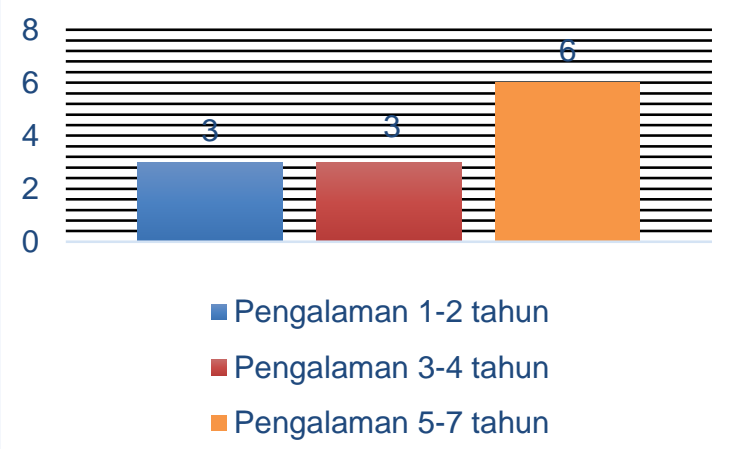

Gambar 3. Rata-rata Pengalaman Kerja 


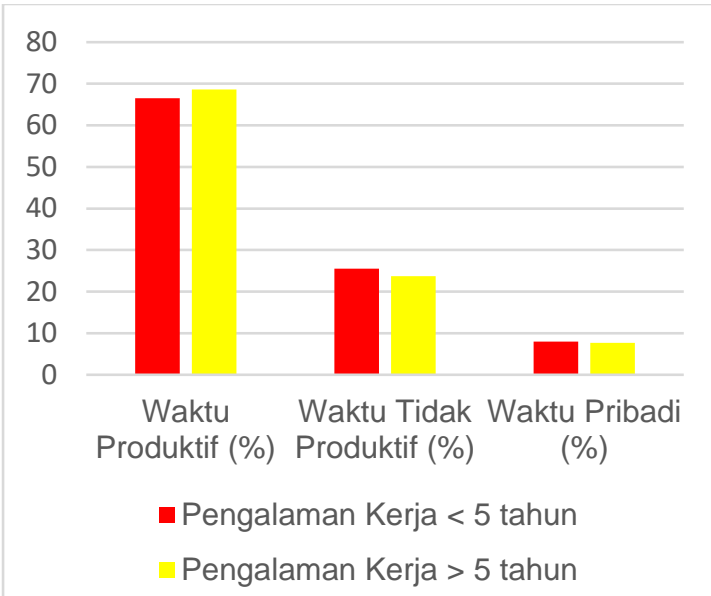

Gambar 4. Rata-rata Perbandingan Pengalaman Kerja

Dari grafik di atas terlihat bahwa perbandingan pengalaman kerja yang di dapat adalah waktu produktif untuk karyawan kurang dari 5 tahun 66,49\% lebih rendah dari pada karyawan lebih dari 5 tahun $68,60 \%$, untuk waktu tidak produktif karyawan kurang 5 tahun $25,57 \%$ lebih tinggi dari pada karyawan lebih dari 5 tahun $23,74 \%$, dan waktu pribadi karyawan kurang dari 5 tahun $7,94 \%$ lebih tinggi dari pada karyawan lebih dari 5 tahun $7,66 \%$. Dengan masa kerja yang banyak maka mencerminkan pengalaman kerja yang baik karena semakin banyak pengalaman yang didapatkan karyawan akan semakin terlatih dan terampil dalam melaksanakan pekerjaannya. g. Karakteristik Berdasarkan Tingkat Pendidikan

Tingkat pendidikan seseorang pada prinsipnya akan mempengaruhi kebutuhan, nilai-nilai yang dianut, cara pandang dan persepsi terhadap suatu persoalan. Hasil analisis menunjukkan bahwa tingkat pendidikan sebanyak 3 karyawan berpendidikan SMA, 3 $\begin{array}{lll}\text { karyawan berpendidikan SMP, } 6 & \end{array}$ karyawan berpendidikan SD

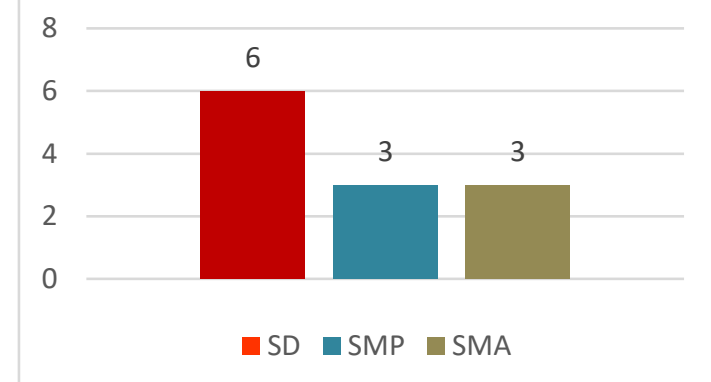

\section{Gambar 5. Rata-rata Tingkat Pendidikan}

\section{h. Penggunaan Waktu Kerja Karyawan} Pemupukan

Pengamatan dilakukan selama jam kerja dengan jarak waktu pengamatan setiap 10 menit yang dilakukan selama 7 jam waktu kerja selama 3 hari untuk masing-masing karyawan. Hal ini bertujuan untuk mengetahui persentase seorang karyawan menggunakan jam kerja mereka untuk bekerja dan tidak bekerja. Berikut hasil pengamatan penggunaan waktu kerja dengan metode work sampling.

Tabel 4. Waktu Kerja Karyawan Pemupukan Afdeling I

\begin{tabular}{ccccccc}
\hline \multirow{2}{*}{ Responden } & \multicolumn{3}{c}{ Total Waktu (Menit) } & \multicolumn{3}{c}{ Persentase \% } \\
\cline { 2 - 7 } & Produktif & Tidak Produktif & Pribadi & Produktif & $\begin{array}{c}\text { Tidak } \\
\text { Produktif }\end{array}$ & Pribadi \\
\hline KPpk1 & 293 & 94 & 32 & 69,84 & 22,46 & 7,70 \\
\hline KPpk2 & 279 & 107 & 34 & 66,51 & 25,48 & 8,02 \\
\hline KPpk3 & 279 & 108 & 33 & 66,35 & 25,79 & 7,86 \\
\hline KPpk4 & 273 & 112 & 35 & 64,92 & 26,75 & 8,33 \\
\hline KPpk5 & 284 & 103 & 33 & 67,62 & 24,60 & 7,78 \\
\hline KPpk6 & 258 & 128 & 34 & 61,43 & 30,48 & 8,10 \\
\hline KPpk7 & 294 & 95 & 31 & 70,08 & 22,54 & 7,38 \\
\hline KPpk8 & 289 & 98 & 33 & 68,81 & 23,33 & 7,86 \\
\hline KPpk9 & 278 & 108 & 34 & 66,27 & 25,71 & 8,02 \\
\hline KPpk10 & 290 & 99 & 31 & 68,97 & 23,57 & 7,38 \\
\hline KPpk11 & 296 & 93 & 31 & 70,48 & 22,14 & 7,38 \\
\hline KPpk12 & 291 & 97 & 32 & 69,29 & 23,02 & 7,70 \\
\hline Jumlah & 3404 & 1243 & 393 & & & 7,80 \\
\hline Rata Rata & 283,69 & 103,56 & 32,75 & 67,55 & 24,66 & \\
\hline
\end{tabular}


Dari hasil penelitian jumlah penggunaan waktu untuk masingmasing karyawan kegiatan yang dilakukan Karyawan Pemupukan (KPpk) diketahui bahwa jumlah waktu untuk kategori kegiatan produktif adalah berkisar dari $61,43 \%$ hingga $70,48 \%$, sementara untuk kegiatan tidak produktif berkisar dari $22,14 \%$ hingga $30,48 \%$, lalu untuk kegiatan pribadi berkisar dari $7,38 \%$ hingga $8,33 \%$.

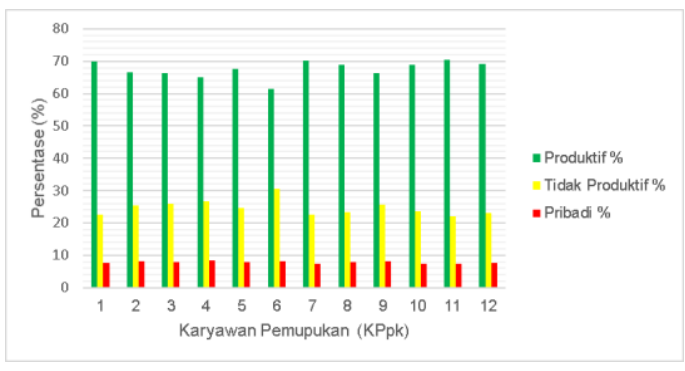

Gambar 6. Data Penggunaan Waktu Kerja Karyawan Pemupukan

Berdasarkan hasil grafik di atas, diketahui bahwa karyawan yang waktu produktif paling tinggi ialah karyawan pemupukan 11 yaitu $70,48 \%$ dan karyawan yang waktu produktif paling rendah ialah karyawan pemupukan 6 yaitu 61,43\%. Diketahui bahwa karyawan yang waktu tidak produktif paling tinggi ialah karyawan pemupukan 6 yaitu $30,48 \%$ dan karyawan yang waktu tidak produktif paling rendah ialah karyawan pemupukan 11 yaitu 22,14\%. Diketahui bahwa karyawan yang waktu pribadi paling tinggi ialah karyawan pemupukan 4 yaitu $8,33 \%$ dan karyawan yang waktu pribadi paling rendah ialah karyawan pemupukan 7, 10 dan 11 yaitu 7,38\%. Dari ketiga aspek di atas tidak menunjukkan perbedaan yang jauh antar karyawan pemupukan.

Hal ini dikarenakan karyawan bekerja sebagai tim (4 orang/tim), dimana ketika salah satu karyawan melepas lelah atau minum maka rekan kerjanya juga istirahat.

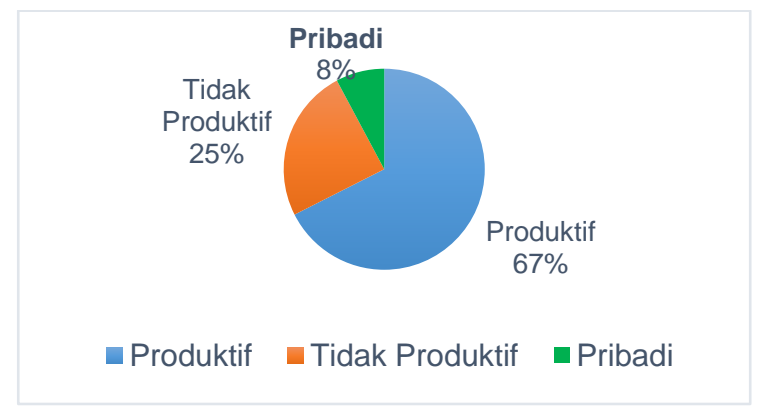
Gambar 7. Grafik Rata-rata Penggunaan Waktu Kerja (\%)

Dari diagram lingkaran diatas terlihat bahwa pencapaian target kerja produktif rata rata hampir mencapai $70 \%$. Dapat disimpulkan bahwa ratarata persentase waktu produktif karyawan pemupukan sebesar 67\% faktor yang menyebabkan karyawan memiliki jam produktif adalah pertama karena memiliki jiwa yang disiplin, bekerja sesuai dengan ketentuan perusahaan yang ada, taat pada peraturan yang telah ditetapkan, waktu tidak produktif sebesar $25 \%$ faktor karyawan memiliki jam tidak produktif adalah pembicaraan antar karyawan yang membahas selain pekerjaan dan adanya sinyal jaringan di tempat tertentu membuat karyawan tidak fokus bekerja dan waktu pribadi sebesar $8 \%$ yang meliputi faktor memakan perbekalan yang dibawa dan mengistirahatkan diri agar tidak kelelahan.

\section{E. Analisis Kebutuhan Karyawan} Analisis mengenai jumlah kebutuhan karyawan untuk pekerjaan pemupukan dilakukan dengan menggunakan metode perhitungan kebutuhan tenaga kerja berdasarkan beban kerja.

Langkah-langkah perhitungan kebutuhan tenaga kerja berdasarkan beban kerja sesuai Keputusan Menteri Pendayagunaan Aparatur Negara Nomor : KEP/75/M.PAN/7/2004 yaitu sebagai berikut :

1. Menetapkan Waktu Kerja 
Berdasarkan hasil observasi, karyawan yang bekerja pada divisi pemupukan di afdeling satu bekerja selama empat hari dalam seminggu dari hari Senin hingga Kamis. Untuk hari Jum'at, Sabtu dan Minggu karyawan pemupukan diliburkan karena efisiensi hari kerja (harga minyak sawit sedang turun). Adapun jam kerja karyawan per hari yaitu sejak pukul 07.00 sampai dengan pukul 14.00 WITA (waktu istirahat pukul 10.30-11.00). Waktu kerja efektif dihitung dengan menentukan jumlah hari dalam setahun, jumlah Jum'at, Sabtu dan Minggu dalam setahun, jumlah cuti dalam setahun, dan jumlah hari libur nasional dalam setahun. Kemudian jumlah hari Jum'at, Sabtu dan Minggu ditambahkan dengan jumlah hari libur nasional dan cuti tahunan yang menghasilkan total hari tidak bekerja atau libur, lalu jumlah hari dalam setahun itu dikurangi dengan total jumlah hari tidak bekerja. Rumusan perhitungan hari kerja efektif sebagai berikut :

Tabel 5. Hari Kerja Efektif Karyawan Pemupukan PT. WIN Tahun 2019

\begin{tabular}{|c|c|c|c|c|c|c|}
\hline No & Bulan & $\begin{array}{l}\text { Jumlah } \\
\text { Hari }\end{array}$ & $\begin{array}{l}\text { Libur Hari } \\
\text { Jumat, Sabtu } \\
\text { \& Minggu }\end{array}$ & $\begin{array}{l}\text { Libur } \\
\text { Nasional }\end{array}$ & Cuti Tahunan & $\begin{array}{l}\text { Hari Kerja } \\
\text { Efektif }\end{array}$ \\
\hline 1 & Januari & 31 & 11 & 1 & - & 19 \\
\hline 2 & Februari & 28 & 11 & 1 & - & 16 \\
\hline 3 & Maret & 31 & 14 & 1 & - & 16 \\
\hline 4 & April & 30 & 10 & 2 & - & 16 \\
\hline 5 & Mei & 31 & 11 & 3 & - & 19 \\
\hline 6 & Juni & 30 & 12 & 6 & - & 15 \\
\hline 7 & Juli & 31 & 9 & - & 7 & 15 \\
\hline 8 & Agustus & 31 & 13 & 2 & - & 16 \\
\hline 9 & September & 30 & 13 & 2 & - & 16 \\
\hline 10 & Oktober & 31 & 12 & - & - & 19 \\
\hline 11 & November & 30 & 13 & - & - & 16 \\
\hline 12 & Desember & 31 & 12 & 2 & - & 18 \\
\hline Jumlah & 365 & 134 & 20 & 7 & 204 & \\
\hline
\end{tabular}

Sumber : Kominfo.go.id 2019

Hasil perhitungan menunjukkan bahwa total hari dalam satu tahun sebanyak 365 hari, lalu jumlah hari dikurangi dengan hari libur Jum'at, Sabtu dan Minggu sebanyak 141 hari, libur nasional sebanyak 13 hari dan cuti tahunan 7 hari sehingga diperoleh jumlah hari kerja efektif karyawan yaitu sebanyak 204 hari.

Karyawan Pemupukan bekerja selama 7 jam per hari 420 menit atau sebanyak 1.680 menit per minggu (7 jam dikalikan dengan empat hari kerja). Jam kerja efektif adalah jumlah jam kerja formal dikurangi dengan waktu kerja yang hilang karena tidak bekerja (allowance) seperti menunggu pupuk yang akan datang dari gudang, buang air, melepas lelah, istirahat makan, dan sebagainya. Allowance diperkirakan rata-rata sekitar $30 \%$ (10\% Fatigue Allowance dan 20\% Delay Allowance) dari jumlah jam kerja
(Wignjosoebroto, 2000). Dengan demikian, jam kerja efektif Karyawan Pemupukan setelah dikurangi allowance $(1.680 \times 70 \%)$ menjadi 294 menit/hari atau 1.176 menit/minggu atau 59.976 menit/tahun.

\section{Menyusun Waktu Penyelesaian Tugas \\ Setiap pekerjaan harus diukur waktu yang digunakan untuk} penyelesaian tugasnya. Oleh karena itu, pekerjaan harus dapat diukur dan dihitung dalam satuan waktu tertentu sehingga penyelesaian tugas dapat efektif dan efisien. Efektif terlihat dari tercapainya tujuan menggunakan waktu yang telah ditetapkan sebelumnya dan efisien tidak lain mengandung dua makna, yaitu : makna pengurangan waktu yang ditentukan, dan makna investasi waktu menggunakan waktu yang ada. Waktu Penyelesaian Tugas 
(WPT) diperoleh dengan mengalikan Beban Tugas (BT) dua belas bulan dan Standar Kemampuan Rata-rata (SKR), yang kedua data tersebut diperoleh data sekunder berupa penghitungan kebutuhan pegawai berdasarkan beban kerja

Tabel 6. Waktu Penyelesaian Tugas Karyawan Pemupukan

\begin{tabular}{|c|c|c|c|c|c|}
\hline No & Uraian Tugas & BT (Hari) & BT (Tahun) & SKR & WPT (Menit per tahun) \\
\hline 1 & Apel Pagi & 1 Kali & 204 & 10 Menit & 2.040 \\
\hline 2 & $\begin{array}{l}\text { Mempersiapkan } \\
\text { Alat Kerja }\end{array}$ & 1 Kali & 204 & 5 Menit & 1.020 \\
\hline 3 & $\begin{array}{l}\text { Mengenakan } \\
\text { Alat Pelindung } \\
\text { Diri }\end{array}$ & 1 Kali & 204 & 5 Menit & 1.020 \\
\hline 4 & $\begin{array}{l}\text { Menuju Blok } \\
\text { Atau Lokasi } \\
\text { Kerja }\end{array}$ & 1 Kali & 204 & 10 Menit & 2.040 \\
\hline 5 & $\begin{array}{l}\text { Membuka } \\
\text { Karung Pupuk }\end{array}$ & 7 Kali & 1.428 & $\begin{array}{l}2 \\
\text { Menit/Kar } \\
\text { ung }\end{array}$ & 2.856 \\
\hline 6 & $\begin{array}{l}\text { Menuang } \\
\text { Pupuk Ke } \\
\text { Dalam Ember }\end{array}$ & 14 Kali & 2.856 & $\begin{array}{l}2 \\
\text { Menit/Tua } \\
\text { ng }\end{array}$ & 5.712 \\
\hline 7 & $\begin{array}{l}\text { Mengangkat } \\
\text { Ember Yang } \\
\text { Telah Di Isi } \\
\text { Pupuk }\end{array}$ & 14 Kali & 2.856 & 1 Menit & 2.856 \\
\hline 8 & $\begin{array}{l}\text { Berjalan dan } \\
\text { menabur pupuk } \\
\text { pada areal } \\
\text { piringan pokok } \\
\text { sawit }\end{array}$ & 7 Karung & 1.428 & $\begin{array}{l}15 \\
\text { Menit/Kar } \\
\text { ung }\end{array}$ & 21.420 \\
\hline 9 & $\begin{array}{l}\text { Berjalan } \\
\text { Kembali Untuk } \\
\text { Mengisi Ember } \\
\text { Pupuk }\end{array}$ & 14 Kali & 2.856 & 5 Menit & 14.280 \\
\hline 10 & $\begin{array}{l}\text { Perpindahan } \\
\text { Jalur } \\
\text { Berikutnya }\end{array}$ & 7 Kali & 1.428 & 5 Menit & 7.140 \\
\hline & $\Sigma$ WPT & & & 60.384 & \\
\hline
\end{tabular}

Divisi I luas Areal 737 ha,

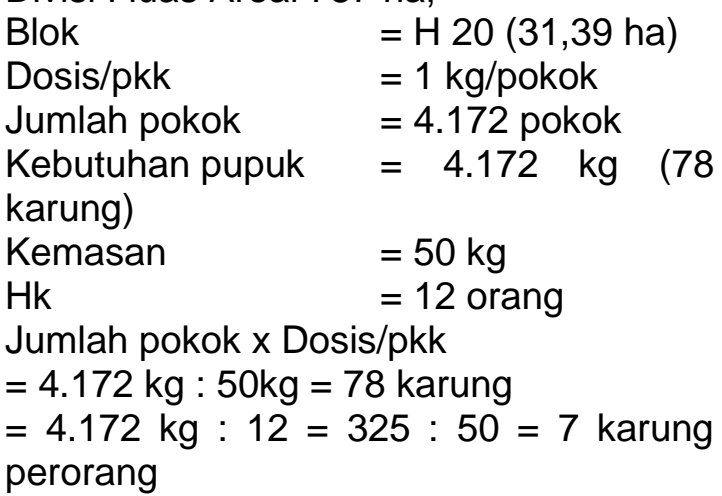

Output Hk/ha = Luas lahan : Hk

$=31,39 \mathrm{ha}: 12 \mathrm{Hk}=2,6 \mathrm{ha} / \mathrm{hk}$

$=2,6$ ha $\times 136 \mathrm{pkk}$

$=353,6$ pokok $/ \mathrm{Hk}$

Sumber : Rekomendasi Pemupukan Afdeling 1 PT.WIN

3. Jumlah Kebutuhan Karyawan Pemupukan

Berikut perhitungan jumlah kebutuhan karyawan pemupukan afdeling satu 
Kebutuhan Karyawan

$$
\begin{aligned}
& =\frac{\sum \text { Waktu Penyelesaian Tugas }}{\sum \text { Waktu Kerja Efektif }} \times 1 \\
& \frac{60.384}{59.976} \times 12=(12,08) \approx 13 \text { orang }
\end{aligned}
$$

Jadi dengan jumlah 13 orang karyawan pekerjaan pemupukan kelapa sawit dapat dilaksanakan. Jumlah angka tersebut sudah sesuai pada ketentuan Standar Operasional Perusahaan (SOP), karena pada perusahaan tersebut terdapat 8 afdeling. Beban kerja dibagi menjadi tiga kondisi yaitu beban kerja normal (fit), beban kerja yang terlalu berlebih (overload) mengindikasikan bahwa jumlah pekerja yang dipekerjakan tidak sesuai dengan beban kerja yang diterima sehingga dapat menyebabkan kelelahan fisik maupun psikologis yang berakibat pada menurunnya produktivitas karena kelelahan bekerja dan Sedangkan beban kerja yang terlalu rendah (underload) mengindikasikan bahwa jumlah pekerja yang dipekerjakan terlalu banyak sehingga perusahaan harus mengalokasikan biaya untuk gaji karyawan lebih banyak dengan tingkat produktivitas yang sama.

Berdasarkan grafik di atas, jumlah karyawan pemupukan yang berada di afdeling satu (aktual) 16 Karyawan dan orang yang diteliti (responden) berjumlah 12 orang. Hasil dari perhitungan jumlah kebutuhan karyawan diperoleh hasil 13 orang yang diperlukan untuk pekerjaan pemupukan pada afdeling satu. Jadi dengan 13 orang pekerja bisa melaksanakan kegiatan pemupukan kelapa sawit di afdeling tersebut.

\section{Implikasi Manajerial}

Perhitungan kebutuhan karyawan berdasarkan beban kerja karyawan bagian pemupukan di afdeling satu, merupakan salah satu dasar dari perencanaan Sumber Daya Manusia (SDM) pada PT.WIN. Kesalahan perencanaan sumberdaya manusia dapat mengakibatkan dampak negatif terhadap PT.WIN seperti besarnya biaya tetap yang dikeluarkan untuk sumber daya manusia yang tidak berkompeten, tidak efisien dan efektif dalam bekerja.
Kelebihan jumlah karyawan merupakan salah satu masalah yang perlu diperhatikan oleh PT.WIN, karena dapat memicu ketidak efisienan perusahaan, terutama dalam pembiayaan SDM. Terdapat beberapa upaya dalam mengatasi permasalahan tersebut antara lain :

a. Meningkatkan pengawasan, hal ini bertujuan untuk meminimumkan jumlah penggunaan waktu kerja yang tidak produktif.

b. Memberikan tambahan tugas pekerjaan pada bagian pemupukan, sehingga meningkatkan jumlah aktivitas karyawan.

\section{KESIMPULAN}

Berdasarkan hasil analisis dan pembahasan yang telah dilakukan maka kesimpulan yang dapat diambil sebagai berikut :

1. Deskripsi pekerjaan dari masingmasing karyawan pada divisi pemupukan afdeling satu jelas dan ditetapkan oleh PT Wira Inova Nusantara. Penetapan ini sudah diimplementasikan oleh karyawan berdasarkan tugas dan tanggung jawabnya masingmasing.

2. Berdasarkan perhitungan didapatkan 204 hari kerja efektif selama setahun dengan waktu kerja efektif yang dimiliki oleh karyawan pemupukan diafdeling 1 adalah 59.976 menit per tahun.

3. Masing-masing karyawan pemupukan sudah dihitung beban kerja berdasarkan waktu kerja efektif. Secara umum rata-rata persentase total beban kerja yang dimiliki adalah $67 \%$ waktu produktif $25 \%$ tidak produktif dan $8 \%$ waktu pribadi. Jumlah kebutuhan karyawan pemupukan setelah dilakukan perhitungan adalah 13 pekerja pada satu afdeling.

\section{DAFTAR PUSTAKA}


Barnes, R.M. 1980. Motion And Time Study Design And Measurement Of Work Seventh Edition. United State Of America : Quinn - Woodbine, Inc.

Bary, M. A. 2013. "Analisis Beban Kerja Dan Kolerasinya Terhadap Produktivitas Kerja Pada Proses Produksi CPO Di PMS Semuntai PTPN XIII Pasir, Kalimantan Timur". [Tesis]. Bogor: (ID): Institut Pertanian Bogor.

Bary, M.A., Syuaib, M.F., Rahmat, Muchlis. 2013. "Analisis Beban Kerja Pada Proses Produksi Crude Palm Oil (CPO) Di Pabrik Minyak Sawit Dengan Kapasitas 50 Ton Tbs/Jam". Jurnal Teknologi Industri Pertanian. Vol. 23, No. 3:220-231

Handoko S., Putri N.T., Jonrinaldi. 2017. "Analisis Beban Dan Kebutuhan Tenaga Kerja Di Biro Pengadaan Barang Pt. Semen Padang". Jurnal Optimasi Sistem Industri. VOL. 16 NO. 2 (2017) 140-149. http://josi.ft.unand.ac.id/. 27 September 2017.

Mangoensoekarjo. S dan Semangun. $\mathrm{H}$. 2000. "Manajemen Agrobisnis
Kelapa Sawit”. Edisi 1:330. Jakarta. Penerbit Gadjah Mada University Press

Naibaho PM. 1998. "Teknologi Pengolahan Kelapa Sawit". Medan : Pusat Penelitian Kelapa Sawit.

Pahan, I. 2012. "Panduan Lengkap Kelapa Sawit". Jakarta : Penerbit Swadaya. 146 hal

Risza, S. 1994. "Kelapa Sawit Upaya Peningkatan Produktivitas". Yogyakarta : Penerbit Kanisius.

Sunarko, 2014. "Budi Daya Kelapa Sawit Di Berbagai Jenis Lahan". Jakarta : PT AgroMedia Pustaka. 19 hal

Sugiyono, 2008. "Metode Penelitian Kuantitatif Kualitatif dan R\&D". Bandung : Alfabeta

Suwatno, H., Priansa., Donni. 2011. "Manajemen Sumber Daya Manusia, Dalam Oranisasi Publik dan Bisnis". Bandung : Alfabeta

Wignjosoebroto, S. 2000. "Ergonomi Studi Gerak Dan Waktu Edisi Pertama Catatan Kedua". Surabaya : Penerbit Guna Widya. 